\title{
The affective and affectless bodies of monster toon porn
}

Susanna Paasonen

Monster (car)toon porn is a genre of 3D computer-generated pornography that focuses on depictions of sexual encounters of the impossible and improbable kind. In monster toon porn, demons, zombies and hulk-like creatures copulate with elves, Hollywood starlet look-alikes and female game characters, huge bodies penetrate tiny ones and human-like bodies sprout novel sexual organs. Broadly building on the combined traditions of Western cartoon porn, Japanese hentai and ero-manga (pornographic anime and comics) and machinima (3D videos generated in real time with game engines and, increasingly, with the aid of additional software), monster toon porn is often classified as hentai, independent of its factual geographical origins. Its imageries are characteristically fantastic and excessive in their displays of spectacularly incompatible bodies engaging in penetrative sex, in its scenarios of control and submission and in its displays of lust and disgust seemingly knowing no bounds. These images and videos originate from the efforts of amateur fans, commercial studios and crowdfunded non-profit enterprises alike.

Zooming in on this landscape, this chapter explores monster toon porn in terms of both its irregular embodiments and their uncanny lack of affect, and considers how these nonhuman displays of sexualised and gendered dynamics of control connect to game culture. These considerations are tied in with a discussion on the specificities of digitally generated and distributed pornography in terms of media technology, labour and ethics. Specific focus will be paid on the oeuvre of Studio FOW specialized in crowdfunded Source Filmmaker (SFM) hentai monster videos set in game worlds.

The hyperboles of animated porn 
The histories of modern pornography preceding photographic technologies linger back to the traditions of erotic literary fiction and the visual arts spanning engravings, graphic prints, drawings and paintings. In addition to attempting to sexually arouse their audiences, these have equally aimed at amusement through the means of exaggeration, mockery and excess. Some visual pornography - as in the format of paintings - was produced for the exclusive private amusement of wealthy male clientele whereas prints were in much broader circulation, especially after the introduction of inexpensive printing presses in the late 18 th century. In visual pornography, penises, vaginas and various other body parts have set off on adventures, detached themselves from bodies, floated about, changed shape and copulated creatively for a number of centuries. In the early 20th century, this visual tradition expanded to sexually explicit comics, such as the 1930s "Tijuana Bibles" featuring pornographic variations of popular mainstream comic strips and celebrities (see Pilcher 2008; Adelman 1997; also Uidhir and Pratt 2012). In animated film - an emergent art form characterised by visual simplification, surface, rhythm and repetition (Klein 1998) - graphic pornography met the possibilities of moving image. Film scholar Constance Penley $(2004,318)$ identifies ribald humour, wanton penises, "hyperbolically exaggerated body parts and wildly impossible sexual positions" ubiquitous in these comics as equally standard elements of early animated pornographic film.

Among these, Eveready Harton in Buried Treasure, composed in 1928-29 and attributed to the virtual production studio Climax Fables, was one of the very first. In the six-minute film, Eveready Harton's expansive penis escapes his body, hides behind rocks, functions as a third leg, gets attacked by a plate-sized crab louse during penetration, gets stuck in a man's anus, bents, is hurt by cacti and, in the film's happy end, gets licked by a cow. The film is rife with puns, bodily metamorphoses and hyperbolic body parts while the boundaries of the animate 
and the inanimate, human and animal, are in constant flux. As Jose B. Capino $(2004,59)$ points out, "just as animals, plants and humans communicate and play with each other in mainstream animation, so also do the figures in animated pornography speak the same language of polysexual desire and perform more sexual roles than conventional human morality can tolerate".

In the German, undated Super 8 film loop most likely dating back to the late early 1970s, titled Schwänzel und Gretel (also known in English as Dickzel and Gretel and Hans and Gretel in the Magic Forest), trees and roofs of houses sprout human-like sexual organs, penises grow from the ground and people, squirrels, owls and pigs all engage in continuous orgies (also Capino 2004, 57). This pornographic fantasyland is one of hyperbolic, excessive and even compulsive sexuality where ejaculate oozes from unsuspected outlets and lubricates the narrative action. The film is part of a broader cycle of German animated porn revisiting classic cartoons, from the Western adventures of Puffalo Bill to Robert Keller und Dieter Hahn where Max and Moritz play out some of their more adult tricks, Rammel der Hase featuring an amply endowed Bugs Bunny of sorts and Schneeflittchen und die 7 Zwerge where Snow White engages in group sex with the seven dwarfs and shoots pickles from her vagina. All these cartoons aim to titillate through their sexual explicitness but much more centrally to entertain through their surprising twists and turns, metamorphosing bodies and unequivocally smutty forms of humour.

Animated porn has since taken virtually endless shapes and forms, from parody versions of popular children's animation gone wild to fan-made machinima created out of The Sims and the $3 \mathrm{D}$, high-resolution bodies approximating photorealistic aesthetics and representing the higher end in terms of production value. Alongside these, all kinds of pornographic comics and still images abound in resolutions high and low, in genres more and much less 
mainstream and in aesthetics ranging from the cartoonish to the photorealistic. Digital image manipulation and animation tools have grown increasingly accessible. At the same time, all kinds of pornographic animations are more readily available than ever on online video sharing platforms. These aggregate or tube sites enable the uploading, and hence the public archiving, of clips that were previously in much narrower circulation through screenings, VHS and DVD compilations. The "affective processing" of "digital ephemera" (Gehl 2011) on tube sites gives rise to heterogeneous archives of varying copyright statuses. Individual clips are detached from their original contexts of production and distribution, titled, described and tagged as users see fit (Gehl 2009, 46-47). This regularly results in an efficient erosion and loss of metadata, production data included. The titles of films may be missing or replaced with others while there is generally little information available on when the films were made, where and by whom. And, given the diverse routes of circulation that online content takes across tube sites, paywall protected services and torrent platforms, the origins of individual clips can be hard to track indeed.

In the horizontal space of tube archives, both those specializing in animated pornography and those catering to virtually all tastes, one may move from Pokemon hentai featuring some of Pikachu's more raunchy moments to porn variations of Family Guy, Simpsons and Futurama. In these, family members get it one with one another and the boundaries of species, as well as those of humans and machines, are overcome with gusto. Some tube sites feature all kinds of cartoon porn whereas others focus more exclusively on hentai, itself tagged under categories such as schoolgirls, tentacles, goblins, furries, futanari (intergender pornography where primary sexual characteristics of different genders are played with) and those familiar from other realms of pornography, such as "anal", "BDSM", "blowjob” or "gangbang". 
Mark McLelland (2005) points out that, in Japanese, the term hentai refers only to sexual materials deemed unusual, extreme or abnormal. Such scenarios might involve "number of partners as in gang rape, or bizarre partners as in aliens or monsters or illicit partners as in children." At the same time, Japanese pornographic anime more broadly involves narratives tied in with "the fantastic, the occult, or science fiction" and regularly privileges "the female body in pain" in scenes of sexual torture and mutilation (Napier 2005, 64). This also applies to eroge, hentai computer games with their perennial - and perennially controversial - themes of incest and sexual violence that have grown part of global gaming cultures (Martinez and Manolovitz 2010). For while some eroge remains relatively softcore, other releases veer firmly towards guro - that which Urban Dictionary defines as "grotesque pornography" involving "diarrhoea ( $\mathrm{sic}$ ) scat, necrophilia, amputee sex, skull-fucking and violent rape" (http://www.urbandictionary.com/define.php?term=guro; for a contemporary portfolio of eroge, see https://www.lewdgamer.com/).

Despite referring to sexual depictions of the more extraordinary and unlikely kind, in the Japanese context, hentai does not have a pejorative connotation similar to that of abnormality and perversion in Western scientia sexualis (McLelland 2005; cf. Foucault 1991; Foucault 2003). While hentai was considered too extreme or plain bizarre for Western pornographic DVD markets of the 1990s, it quickly gained ubiquitous recognizability on online platforms, followed by broad, multi-platform distribution (see Dahlqvist and Vigilant 2004). Mariana Ortega-Bena $(2009,20)$ defines hentai through characteristics such as "substandard animation, ample dwelling on unconventional erotic practices, a fixation on rape and nonconsensual sexual violence, and often preposterous scenarios", but also associates it with the grotesque and carnivalesque features of Japanese erotic fiction that veer towards the bizarre while making use of humour. 
Building on the tradition of shunga, erotic woodblock prints, which peaked during the Edo period (1603-1868), hentai richly features many of its themes, such as "Massive genitalia, ingenious sexual aids, couplings of all kinds, a wide array of fetishes, bizarre viewpoints, physical anomalies, bawdy comedy, and satirical vignettes" (Ortega-Bena 2009, 20). The influences of shunga remain evident in hentai, from exaggerated physical characteristics to humour and elaborate scenarios of tentacle rape (see Screech 2009; Buckland 2010; Gerstle and Clark 2013; Kazutaka 2013; Napier 2005, 21). The uses of tentacles and other non-human phallic shapes owes partly to Japanese legislation banning the showing of genitalia without pixelation (see Hambleton 2015; Napier 2005, 79). Pixelation occurs in a range of monster toon porn, which may speak of Japanese origins or compliance with local regulation for distributing the content. The landscape of monster toon porn is populated by tentacle monsters owing to Hokusai's classic woodcut, The Pearl Diver (a.k.a., The Dream of the Fisherman's Wife, 1814), as well as a vast range of giant worm-like creatures, demons, centaurs, elves, ogres, dragons, zombies and amalgamations of humans and bugs. The genre can be identified as posthuman in a range of ways: due to its nonhuman and hybrid protagonists that often metamorphose from one shape to another, its computer-generated origins resulting from algorithmic functions and its affectless bodies engaging in mechanical sexual acts.

Like hentai, monster toons are rife with "demonic phallus incarnate": namely demonic characters that are "preternaturally huge, covered with rippling muscles, and inevitably equipped with an enormous penis (and often with phallic tentacles as well)" (Napier 2005, 65, 79). Be these monsters insects, spiders, fishes, slugs, extraterrestrial creatures or demons, narrative action focuses firmly on vaginal, oral and anal penetrative sex that climaxes in money shots. Monsters of all kinds sport highly anthropomorphic penises, semen flows freely 
from all kinds of bodies and anthropomorphic female characters grow pregnant with bugs and demons alike.

The landscapes of action are mostly dungeons and simplified forests - spaces routinely featured in the games on which machinima builds - or other abstract spaces void of any excessive detail, let alone markers of everyday life. The sexual scenarios are overwhelmingly ones of domination and submission, often of the non-consensual sort. With the exception of futanari, it is generally the female bodies - young, fit, beautiful and firmly human-like as they tend to be - that are pushed to their boundaries of physical endurance by the sheer size of the penises, tentacles or objects inserted in their cavities. Monsters three times the size of elves slip excessively sized penises into mouths and vaginas while female bodies bend, flex and accommodate.

A search for "monster toon" on Pornhub, world's leading porn aggregate site, result in 5-6 minute clips with titles such as "Giant Monsters Take Hot Chick" and "Monster Sex on Space Station". In these, sex acts consist of the same motions repeated over and over again, accompanied by the same facial expressions and sounds, or the lack thereof. It is noteworthy also more generally that the bodies of monster toon porn move back and forth in their penetrative acts with notably little variation in gesture or motion. In sum, despite the unlimited possibilities that animation affords in imagining characters engaging in acts impossible for actual human bodies to accomplish, or even survive, the fantastic scenes of monster toon porn are recurrently tied up with highly predictable ways of imagining both sexual scenarios and gendered power dynamics. On the one hand, these scenarios are markedly affective in their visceral attention to (more or less fantastic) bodily detail and in the dynamics of disgust, amusement and sexual arousal that they aim to evoke. On the other hand, 
the monsters and their more or less human partners are regularly affectless in their animated, machinic bodily movements.

In terms of aesthetics, monster toon porn can be rather roughly divided into two main modes, namely high-resolution still images and cartoons aiming at full photorealism in the impossible bodies they depict and machinima videos of much lower technical execution. In both instances, female characters tend to resemble the Realdoll brand of sex dolls in their plastic, ultra-feminine human likeness and functional purpose alike. In still images, the details of bodies are carefully crafted towards a paradoxical sense of verisimilitude, from the pores of the skin to the gradations of the soft, hard and the liquid. The bodies of videos, for the most part, remain much more sketch-like. As is the case with Realdolls, the animated characters' facial expressions tend to be vacuous. Their verbal output remains limited to the repetitive loops of grunts, sighs, squeals and whimpers that are largely detached from the motion of bodies, mouths and faces. Like elsewhere in animated pornographic film, human voice is both an extension and displacement of the animated body (Capino 2004, 64) that creates as much distance as it yields grains of proximity. According to Ortega-Bena, hentai follows the more general trend of emotional inexpression, a visual blankness of sorts, in Japanese arts and film. There is little explicit or outward expression of emotion and animated bodies tend to be equally impassive.

All this results in layers of spectacle and excess, blankness and inexpression that are deployed in conveying the markedly fantastic and out-of-the-ordinary (Ortega-Bena 2009, 20-21). Ortega-Bena $(2009,27)$ sees the bodies of hentai as constantly moving "between dichotomies of male, female; potent, impotent; demonic, human; oppressive, submissive; possessive, possessed; attacker, attacked; sadist, masochist". Although these categories are "ultimately fluid, can be shuffled around and are combined in a variety of ways" (Ortega-Bena 2009, 27), 
in the realm of monster toon porn - independent of the centrality of nonhuman sexual partners - the positions of the submissive and the dominant tend to be clearly cut in gendered terms. While the boundaries of species are routinely crossed, bodies metamorphose from one form to another and novel incarnations are common, gendered lines of control remain much more tenuous and consistent.

Extending the game

3D monster toon porn largely builds on the expressive possibilities of machinima, both in its simpler game-engine based variations and those created with the aid of additional software, such as Source Filmmaker (SFM), which encompasses a broad, and stylistically heterogeneous scene of amateur film practice. Independent of the specific forms it takes, machinima filmmaking is centrally derivative: "audiences look forward to familiar game locations, quests, items, and game-generated characters being reinterpreted by machinima filmmakers" (Falkenstein 2011, 87). In other words, machinima involves a resampling and reimagining of game characters and events, and this is also where a central part of its attraction lies. To a degree, the practice of machinima resembles puppetry, of bending characters into new positions, scenes and motions (cf. Hancock 2011, 32). In the sexually explicit extensions of in-game events, female characters, from Lara Croft to the female cast of Final Fantasy, appear in elaborate scenarios with nonhuman or semihuman partners both originating from the game world and not. The key focus of machinima is firmly on the female characters while the details of the monsters are less of a concern. As Darkcrow of Studio FOW notes, "Once you slap a dick on someone they're pretty much good to go!" (in Hernandez 2015). 
Shared online, machinima is part of a broader ecology of DIY fan videos, mashups, remixes and parodies that results from both fan engagement with popular culture and the accessibility and increasing performance of digital production tools (Ito 2011, 51):

"The socio-technical world of machinima embodies (...) the key characteristics of a thriving amateur creative scene: accessible tools, peer-based feedback and exchange, networked online distribution, spaces for participation for both beginners and experts, diverse exemplars (both creative work and people), and opportunities for competition, recognition and status. (Ito 2011, 53).”

Machinima is generally amateur-made and the rough, "a bit ugly" (Douglas 2014, 333) aesthetic is part of its charm. While it is predominantly shared on YouTube, sexually explicit clips circulate on porn tubes - both ones specialize in cartoon porn, hentai and machinima and "general purpose" aggregate sites such as Pornhub and XVideos. On these sites, videos of drastically varying technical execution compete for viewer attention: from the rough-edged characters with repetitive, bouncy and jerky movements more suggestive of photorealism than conforming to its dictates to the extensively worked, higher production value videos of Studio FOW. Protected by fair use copyright policies as parodies generated for non-profit purposes, these films can be freely downloaded and they reach an audience of millions across tube sites. Studio FOW's productions are enabled by fan contributions and their representatives interact actively with fans on Twitter and Tumblr. Their collaborators include "animators, voice actors, and artists, who have come together to work on video game porn movies as a hobby" (Hernandez 2015). In terms of porn production, all this points to forms of voluntary participation and contribution, sharing and production particular to online platforms. 
Studio FOW's “born digital” films depict spectacular, violent 3D scenes of non-consensual sex between female game characters, monsters, demons, as well as human men. Their bestknown film is the very first one, Lara in Trouble (2014), made from the 2013 game featuring a controversial scene where the Lara Croft manages to escape sexual violence on a deserted island. The film sets Lara in an alternative game event timeline where no escape occurs and she ends up being gang raped until, in the very end, trickster-like, Scout, a character of Team Fortress 2, appears and provides her with a gun (also Hernandez 2015). Hence, according to Studio FOW, "A survivor is born, and a studio is forged as the debut movie from two idiots screwing around in SFM comes to the digital big screen" (http://www.studiofow.com/movie/2). The light-hearted connotation of "idiots" "screwing around" is further echoed in the Studio FOW logo, a horse's head: in all their longer films, a horse head mask, broadly used for humour, trolling and, in a Japanese context, as symbol of the Anonymous, makes a brief cameo appearance. Enthusiastically gesturing Scout similarly appears in these films as a wink to the audience.

The presence of Lara Croft in pornographic machinima is hardly surprising, given the character's remarkable popularity as 3D "virtual celebrity", object of nude patch modding and character widely appropriated in explicit sexual scenarios since the first launch of Tomb Raider in 1996 (e.g. Flanagan 1999; Schleiner 2001; Lancaster 2004). Plenty of ink has been spilled on Lara's possible and impossible embodiments and the more general "hypersexualisation" of female game characters (e.g. Burgess et al. 2007; Stermer and Burkley 2010). Studio FOW is far from being the only machinima maker that routinely places female game characters in scenarios of sexual humiliation and submission, even if their films do this in a more elaborate manner than most. In addition to featuring live-action cosplay with amateur and professional performers dressed up as Lara, tube sites offer animations with Lara Croft "gangbanged brutally by monsters", "destroyed by Ogres" and "fucked by Demon" 
(www.xvideos.com), "fucked in a tomb" and "fucked by orcs" (www.pornhub.com). It is possible to see these scenarios as response to how the changes in the game character from the sexy fantasy model of the 1990s to its current, more fully clothed and physiologically viable incarnation (cf. Chess and Shaw 2015, 216). As the game provides fans with less explicit titillation, they are generating their own sex clips. Given the number of futanari clips where Lara (“or Futa-Lara”) sports a lengthy penis, these clips involve a range of fantasies and embodiments.

Pornographic Lara clips can also be associated with the intense, broad and highly public debates on toxic game culture, its patterns of male privilege and violent exclusion of women (see Consalvo 2012). The misogynistic overtones of game culture have been rendered particularly explicit since the 2014 Gamergate controversy, which involved extensive harassment, shaming, threatening and silencing of women in game journalism, industry and scholarship (see Chess and Shaw 2015; Massanari 2015). As Cherie Todd $(2015,65)$ notes, these women all shared a "critical stance against how girls and women are typically portrayed in games (as submissive, sexualised and victimized characters)" as well as a "stance against the cultural embeddedness of misogynist tendencies present within the gaming industry, in which the majority of employees are men." Framed in this vein, the appropriation of female game characters, no matter how strong and proactive they may be in their respective game worlds, in scenarios of nonconsensual sex comes across as an extension of broader gendered dynamics of game culture.

As Patricia Hernandez (2015) points out, Studio FOW titles are brutal: “After sex scenes, women gush semen or vomit semen endlessly, from just about every orifice at once". According to Studio FOW's director and founder Darkcrow's definition, "We're a team of perverts who love showcasing the slutty side of all your favourite videogame heroines! We 
make short 3D movies featuring iconic babes getting roughed up and being put in lewd situations.” (Raze 2015). Studio FOW's films derive their specific dynamics from game fan cultures, including those cutting through Gamergate. Equally centrally, the studio remains faithful to the conventions of hentai. According to Darkcrow, Studio FOW partly grew out from disillusionment "with the state of the Hentai scene in general, it has really stagnated in terms of the darker, more hardcore content over the past few years so we wanted to bring back a tiny slice of the glory days" (Raze 2015). This fusion of machinima and hentai also has a solid female fan base (Hernandez 2015), which suggests of a more complex entanglement of sexual fantasies, desires and identities than one allowed by a symptomatic reading of Studio FOW through Gamergate and misogyny alone. Sexual fantasies, be these computer-generated or not, often fail to conform to the principles of equalitarianism or good taste in ways that require more nuanced analytical attention.

Fantastic bodies

In addition to Lara in Trouble, the longer Studio FOW titles to date include Kunoichi: Broken Princess (2014) and Kunoichi 2: Fall of the Shrinemaiden (2015), featuring the ninja heroine Kasumi of the Dead or Alive and shrine maiden Momiji of Ninja Gaiden being both raped by and seeking the company of a series of demons, as well as Bioshag: Trinity (2015), Elizabeth from the first-person shooter game, BioShock Infinite, engaging in both consensual and nonconsensual acts with both humans and nonhuman monsters. In addition, the studio releases monthly clips, varying in length from 30 seconds to some minutes, based on different computer games as teasers of future action to be.

The demons in the two Kunoichi films come in varying sizes, from the pint-sized to the humongous impossible confine in rooms sized for humans. In the first film, Kasumi, 
appointed a demon cum dumpster, engages in a series of non-consensual scenes. Some acts occur on stage, some in industrial spaces and others in urban night scenery of apocalyptic Tokyo. As is standard in hentai, Kasumi stomach is shown stretching and bulging from the size of the penises pushed up to her ribcage. Driven to the edge of what her body can do, unable to bear the pain and sure of tearing apart, Kasumi is also driven to orgasm. It is with a demon with a penis well the width of her own thigh and the length of her leg that she ultimately finds sexual abandon. Through this experience, she grows insatiable independent of the hordes of partners involved. In the second film, Kasumi initiates Mumji to a similar narrative procession from non-voluntary abasement to excessive lust.

In her discussion of the first film, Patricia Hernandez (2015) interprets Kasumi's sexual conversion as collapse into "mindbreak state" of voluntary submission. In a different interpretation, Kunoichi films show women gaining urgent carnal desires and pleasures through their extreme experiences and immersion in the liberally flowing demon seed. In this, they follow the more generic conventions of hentai in depicting female bodies as frightening, powerful, mysterious and "controllable only by demons" (Napier 2005, 76). In the Kunoichi films, encounters with demons make the women grow ever stronger, the Kasumi of the second film being somewhat demonic herself.

In comparison, Lara in Trouble is much grittier and, given its focus on human characters, is void of the fantastic demons with penises in different shapes and hues. It is straightforwardly a film about sexual violence: Lara experiences no sexual conversion or revelation in the course of the repeated acts forced on her (even if she is shown vocally enjoying some of them). The narrative framing where she grows stronger as rape survivor remains disjointed in comparison to the preceding action. Despite the visual - both affective and representational plane of sexual extremity, violence and risk, Studio FOW connects these films to work safety. 
For his part, Darkcrow emphasizes the affordances of animation as a safe means to explore violent sexual scenarios:

"This medium allows us to explore fetishes in a safe environment where 3D models are used instead of actual people (...) We aim to make movies for responsible adults... this medium bypasses the seedier facets of the pornography industry. In live action movies the viewer never really knows if the actresses are being exploited, especially in rape fantasies.

We animate digital models in a safe environment, and the voice talent records from the safety of their own homes, which means that our medium is the ideal platform for exploring these darker themes with a clear conscience." (in Hernandez 2015.)

Since all the images are computer-generated, no actual bodies are involved. Contemporary animated porn is basically the work of algorithms and a means of exploring unlikely, fantastic and extreme scenarios impossible to physically act out without censure or bodily harm. In the realm of computer-generated still images and comics, impossible embodiments and brutal scenarios similarly abound. A Google image search for 3D porn comics generates top hits on incest fantasies where minors sport massive genitalia and taboos function as key incentive for action. In animated porn, bodily capacities and desires know no bounds. Its spaces are ones of unlimited and unbridled sexual opulence that no mundane routines or chores disturb. Here, it resembles the tradition of literary pornography in particular (see Marcus 1964).

Animation allows for constant metamorphoses of its "unreal, imaginary, fabricated, virtual" bodies (Capino 2004, 53-54) that are unburdened by gravity, causality or the limits of what 
physical human bodies can do, or be. In addition to bodies fantastically bulging without tearing, bursting or bleeding, their insides can be rendered visible. The motions of penises seen through a woman's body are a specific focus of interest in Studio FOW's titles, as they are in hentai more generally. These are occasionally visualized through small vignettes revealing the motions of the penis inside the body, under the woman skin, flesh and muscle. In these more imaginative uses of animation's possibilities, penises are seen thrusting and ejaculating into vaginas and anuses. In other forms of hentai, bodies can suddenly grow transparent in order to illuminate the action within. In animated porn, the horizons of expressive and imaginary possibility of animation, such as exaggerated gestures, hypertrophied bodies and extreme doses of violence (Capino 2004, 56), meet the excessive and hyperbolic features of pornography.

"Of the many tongues through which pornography speaks the unspeakable, animation is arguably the most articulate and audaciously vulgar. Within the vast corpus of pornographic cartoons, animated bodies can perform every desire and fantasy that the human body cannot utter. Relentlessly and with impunity, the animated body's plastic genitalia and invulnerable orifices grow and multiply, mutate and mutilate, probe or are penetrated by every imaginable object and animal. Sexual boundaries assume the solubility of water colors." (Capino 2004, 54.)

In hentai and ero manga (adult comics), human bodies are regularly pushed to the extremes, even to "the point at which it can be no longer recognized as human" (Shamoon 2004, 87). As Capino $(2004,58,67)$ elegantly points out, there is a limitlessness of fantasy to animated pornography that often meets excessive punitive violence as bodies are mutilated or even annihilated. At the same time, these hyperbolic scenarios of excessive penetration, climax and 
lust involve plentiful instances of humour that is easily downplayed or even ignored when considering their gendered dynamics of submission and domination. Such instances may vary from the overall absurdity of the settings - winged creatures pounding tiny female bodies with their rainbow-hued penises that, impossibly, eventually do fit into the orifices where they are thrust - to the reflective exclamations such as Mumji's understated observation, "This is not normal”, uttered during a particularly rough sex scene with a massive demon.

\section{A laughing matter?}

In the era of free tube sites, pornographic niches, fringes and specialities - in addition to web cams and live streaming - are exceptional as content that consumers are willing to pay for. Despite actors such as Studio FOW sharing their films for no fee, 3D monster toon sites are largely protected by paywalls or on site requiring registration. Clips are made available on tube sites as teasers and advertisements. In addition, monster toon sites attract user attention with the now markedly vintage strategies of metasites (sites that function as directories to other web sites), link sites (sites consisting of external links with little original content) and click-throughs (links leading to endlessly new metasites and link sites). Widely in use before porn consumption began to centralise on aggregate sites - all of which emulate the operating principles of YouTube, launched in 2005 - these strategies for generating traffic, increasing click ratios and attracting users to pay, have since grown much more rare.

The members-only website, Hellywood: Evil Invasion, specializes in glossy, carefully rendered and hyperbolic 3D still images of female celebrities - from Jessica Alba to Lindsey Lohan, Jennifer Aniston and Kate Perry - engaging in elaborate sexual acts with monsters of all kinds. Hellywood promises its paying members access to several affiliate network sites similarly catering in 3D monster and evil forces in sexual play, from "Evil Creatures Fucking 
Cute Girls" to "World of Porncraft 3D”, "Fucked by Evil Creature 3D Video", "3D Evil Attack", "Hell Fuckers", "Fucked by Fiends" and "Live-Action Taboo Tentacles". These sites cater 3D monster toon as video, still images and comics complete with speech bubbles. These notably remediated aesthetics speak of the attraction that such visions hold: despite the abundant accessibility of free video, singular, specialized fantasy images retain their appeal. Monster toon porn features novelties, creatures and extreme acts never seen before. Characterised as celebrity mansion where "a total fucking madness gets a whole new meaning", Hellywood envisions:

"Shocking action-packed 3D hentai scenes of evil creatures from Hell fucking you (sic) favourite award-winning celebrities! Watch hottest women on Earth power-fucked by merciless invaders and gets (sic) orgasm from ugly cock fucking jaw-dropping hentai 3D fantasy scenes right now!”

The female celebrities' faces have been appropriated from mainstream media images - film shots, magazine poses and music video stills - and their expressions range from surprise to disgust, enthusiasm, startle, dismay, joy and panache. The heads often fail to match the bodies modelled for them, many of which come with hyperbolically tiny waists and huge breasts. A legion of computer-generated demons, aliens and other monstrous creatures in greys, greens, blues, blacks and browns is seen probing the celebrities with their perpetually hard penises.

It does not take a huge stretch of analytical imagination to associate the gaping cavities, phallic shapes and metamorphosing bodies of monster toon porn, or the hyperbolic landscape of Studio FOW and the tentacled glossy parallel universe of Hellywood more specifically, with the notion of the grotesque, as introduced by literary scholar Mihail Bahtin in his study of Rabelais. For Bahtin (1984, 30-31, 317), grotesque represents the opposite of classic body 
ideas as limitlessness where the insides and outsides of bodies refuse to be confined within their regular boundaries. The aesthetics of the grotesque intermeshes with and immerses in bodily orifices, exaggerates and in resistant to moderation (Bahtin 1984, 303-304), hence breaking against any conventional notions of proper taste or appropriate demeanour. While carnevalesque excess and unruly laughter are, with Rabelais, connected to the undoing of cultural hierarchies and positions of power, such a symbolic reading is less readily achieved with monster toon porn. Grotesque aesthetics are in broad use and moments of dirty humour abound yet these do not add up as symbolic subversion of social hierarchies of power. All in all, monster toon porn - like pornography more broadly - remains resistant to most readings aiming to pin it neatly down as a cultural symbol or symptom (see Paasonen 2011).

Humour has been elementary to the traditions of graphic pornography preceding film, pornographic animated film, comics as well as shunga and hentai that monster toon porn builds on. Ortega-Bena (2009) highlights the role of humour as adding to the pleasures of hentai and the sense of distance that its emotionally vacuous and expressionless characters contribute to. Much of this applies to Hellywood where facial expressions are frozen in still motion, recombined with computer-generated bodies, smoothed over and set in elaborate scenes of monster orgies. These images are colourful and high-definition, and a great deal of attention has been paid to detail. The resulting effect of follows Capino's $(2004,56)$ more general account of animated porn's impossible, hyperbolic sexual activity as “multiplied in volume, exaggerated in magnitude - resulting in hypersexuality par excellence". The Hellywood effect is literally too much: tongue-in-cheek inasmuch as sexually explicit. The site is richly garnished with invitiation to see "Goblins, walking dead and disgusting creatures of ancient saga invade the Earth to nail every fuckable celeb in the area!"; "Gape on tight celebrity pussies getting ripped by dreadful cocks and filled to the brim with hot infernal 
seed!" and "Watch hell-born vile creatures fuck hot celebrity chicks into complete prostration!"

Such enthusiasm towards evil creatures ripping and nailing hot chicks follows the vocabulary of hardcore porn that attaches unequivocally positive value to the dreadful, vile and disgusting as markers of no holds barred action (see Paasonen 2011, 57-59, 207-209). The huge monsters and tiny elves of monster porn also follow the guiding pornographic principles of spectacularly binary depiction of embodied differences, dynamics of submission and control. The rhetoric of hardcore porn draws firmly on the juxtaposition of the tiny and the colossal, the degenerate and the sweet while firmly amplifying differences in gender, age and ethnicity for the ultimate effect. (Paasonen 2011, 126-128, 157; Capino 2004, 56.) In monster toon porn, this hyperbolic modality grows highly literal as the tiny is truly miniscule and the colossal simply gargantuan.

In many ways, the dramatic, exaggerated and markedly unrealistic scenes and bodies of monster toon porn provide antitheses for amateur pornography, the popularity of which has been one of the major trends in online pornography for the last decade. If amateur porn draws its appeal from a sense of realness, recognisability, familiarity and authenticity, monster toons provide unreal, fantastic and alien scenarios. Meanwhile, its mechanical and machinic motions of bodies pushing back and forth without a great deal of expression, affective nuance or modulations in intensity come across as hyperbolic version of repetition, which has been seen as characteristic of pornography as a genre (e.g. Grosz 2006, 197). Due to all this, monster toon porn remains resistant to literal interpretations based on the premises of realistic representation. 
The heightened sense of fantastic, impossible unrealness, combined with the applications of photorealism, explains much of the appeal of 3D monster toon porn: its excessiveness is impossible to ignore. While immersion in its imageries is undoubtedly possible, a more literal identification with its emotionally vacuous and highly cartoon-like characters is more unlikely. Violent scenarios of submission and control are played out to the fullest, often on overdrive. The resonances that they afford are distinct from those of live-action pornography where the effects of bodies whipped, asphyxiated and stretched are bound up with indexicality - be this experienced as titillating, disturbing or both. In contrast, fantastic computergenerated bodies are endlessly pliable and resilient. The female bodies are perfectly symmetrical, smooth and fine tuned as certain figures of fantasy. They stretch, bounce right back and never fail.

\section{References:}

Adelman, Bob (1997), Tijuana Bibles: Art and Wit in America's Forbidden Funnies, 1930s1950s. New York: Simon \& Schuster.

Bahtin, Mihail. 1984/1965. Rabelais and his world. Trans. Hélène Iswolsky. Bloomington, Indiana University Press.

Buckland, Rosina (2010) Shunga: Erotic Art in Japan. British Museum Press, London. Burgess, Melinda CR, Steven Paul Stermer, and Stephen R. Burgess. "Sex, lies, and video games: The portrayal of male and female characters on video game covers." Sex Roles 57.5-6 (2007): 419-433.

Capino, Jose B. (2004), Filthy Funnies: Notes on the Body in Animated Pornography. Animation Journal 1: 53-71. 
Chess, Shira and Adrienne Shaw (2015), A Conspiracy of Fishes, or, How We Learned to Stop Worrying About \#GamerGate and Embrace Hegemonic Masculinity. Journal of Broadcasting \& Electronic Media 59(1): 208-220.

Consalvo, Mia (2012), Confronting Toxic Gamer Culture: A Challenge for Feminist Game Studies Scholars. Ada: A Journal of Gender, New Media \& Technology 1(1): http://adanewmedia.org/2012/11/issue1consalvo/?utm_source $=$ rss\&utm_medium $=$ rss\&utm_campaign=issue1-consalvo. Dahlqvist, Joel Powell and Vigilant, Lee Garth 2004. "Way Better Than Real: Manga Sex to Tentacle Hentai”. In Dennis D. Waskul (ed.): Net.seXXX: Readings of Sex, Pornography, and the Internet. Peter Lang, New York, 91-103.

Douglas, Nick (2014), It's Supposed to Look Like Shit: The Internet Ugly Aesthetic. Journal of Visual Culture 13(3): 314-339.

Falkenstein, Jun (2011), Machinima as a Viable Commercial Medium. Journal of Visual Culture 10(1): 86-88.

Flanagan, M. (1999). Mobile identities, digital stars, and post-cinematic selves.Wide Angle, 21(1), 77-93.

Foucault, Michel. 1990. The History of Sexuality, Volume 1 - An Introduction. Robert Hurley (trans.). London: Penguin.

Foucault, Michel (2003) Abnormal: Lectures at the Collège de France, 19741975. Marchetti V and Salomoni A (eds.), Burchell G (trans.). New York: Picador.

Gehl, Robert (2009), YouTube as Archive. Who Will Curate This Digital Wunderkammer? International Journal of Cultural Studies 12:1, 43-60. Gehl, Robert W. (2011), The Archive and Processor: The Internal Logic of Web 2.0. New Media \& Society 13(8): 1228-1244. 
Hambleton, Alexandra (2015), When women watch: the subversive potential of femalefriendly pornography in Japan. Porn Studies, published online before print.

Hancock, Hugh (2011), Machinima: Limited, Ghettoized, and Spectacularly Promising. Journal of Visual Culture 10(1): 31-37.

Hernandez, Patricia (2015), The People Who Make Brutal Video Porn. Kotaku, 11 March, http://kotaku.com/the-people-who-make-brutal-video-game-porn-1690892332.

Ito, Mizuko (2011), Machinima in a Fanvid Ecology. Journal of Visual Culture 10(1): 51-54. Kazutaka, Higuchi (2013), No Laughing Matter: A Ghastly Shunga Illustration by Utagawa Toyokuni. Japan Review 26: 239-255.

Klein, Norman M. (1993/1998). 7 Minutes: The Life and Death of the American Animated Cartoon. London and New York: Verso.

Lancaster, Kurt (2004), "Lara Croft: The Ultimate Young Adventure Girl: Or the unending media desire for models, sex, and fantasy." PAJ: A Journal of Performance and Art 26(3): 8797.

Martinez, Michelle and Manolovitz, Tyler (2010), Pornography in Gaming. In Daniel Riha (ed.), Videogame Cultures and the Future of Interactive Entertainment. Oxford: InterDisciplinary Press, 65-74.

Massanari, Adrienne (2015), \#Gamergate and The Fappening: How Reddit's algorithm, governance, and culture support toxic technocultures. New Media \& Society, Published online before print October 9, 2015, doi:10.1177/1461444815608807.

McLelland, M. (2005, July). A short history of 'hentai'. Paper presented at Sexualities, Genders and Rights in Asia: 1st International Conference of Asian Queer Studies. Bangkok, Thailand: AsiaPacifiQueer Network, Mahidol University; Australian National University, http://hdl.handle.net/1885/8673

Napier, Susan J. (2005), Anime from Akira to Howl's Moving Castle: Experiencing Contemporary Japanese Animation. Updated edition. New York: Palgrave. 
Ortega-Brena, Mariana (2009), Peek-a-boo, I See You: Watching Japanese Hard-Core Animation. Sexuality \& Culture 13: 17-31.

Penley, Constance 2004. Crackers and whackers: The white trashing of porn. In Linda Williams (ed..), Porn studies. Durham: Duke University Press, 309-331

Pilcher, Tim (2008), Erotic Comics: A Graphic History from Tijuana Bibles to Underground Comix. New York: Abrams.

Schleiner, Anne-Marie. "Does Lara Croft wear fake polygons? Gender and gender-role subversion in computer adventure games." Leonardo 34.3 (2001): 221-226.

Screech, Timon (2009), Sex and the Floating World: Erotic Images in Japan 1700-1820. Second Edition. London: Reaktion Books.

Shamoon, Deborah. "Office Sluts and Rebel Flowers." In Linda Williams (ed.), Porn Studies. Durham: Duke University Press (2004), 77- 103.

Stermer, Paul S., and Melissa Burkley. "Xbox or SeXbox? An examination of sexualized content in video games." Social and Personality Psychology Compass 6.7 (2012): 525-535. Todd, Cherie (2015), GamerGate and resistance to the diversification of gaming culture. Women's Studies Journal, 29(1): 64-67.

Uidhir, Christy Mag and Henry John Pratt (2012), Pornography at the Edge: Depiction, Fiction, and Sexual Predilection. In Hans Maes and Jerrold Levinson (eds.), Art \& Pornography: Philosophical Essays. Oxford: Oxford University Press, 137-157. 